\title{
SERVIÇOS DE SAÚDE DO TRABALHADOR a co-gestão em universidade pública
}

\author{
GILSON GEHRING-JÚNIOR \\ Stuart Enes Soares \\ Heleno Rodrigues Corrêa-Filho
}

\begin{abstract}
Resumo: Existe incompreensão no meio acadêmico e nos serviços de saúde pública sobre semelhanças e justaposições dos serviços de saúde do trabalhador e dos serviços de saúde suplementares ao Sistema Único de Saúde (SUS) quando contratados por trabalhadores. A co-gestão é apresentada neste artigo como proposta de diferenciar, humanizar, qualificar e compatibilizar a gestão de ambos os serviços.

Palavras-chave: política de saúde; serviços de saúde ocupacional e setor privado; saúde dos trabalhadores.
\end{abstract}

\begin{abstract}
In both academia and the public health sector, misunderstanding exists with regard to the similarities and juxtapositions of workers' health care services and the health care services that supplement the SUS (Unified Health System) when the latter is contracted for by workers. Co-management is presented in this article as an attempt to improve, humanize, and enhance assess to services, while making them more compatible with one another.

Key words: health care policy; occupation health services and the private sector; workers' health.
\end{abstract}

$\mathrm{A}$ tualmente, o setor de saúde sofre conseqüências da globalização devidas, sobretudo, à adoção da política neoliberal. Essa, à medida que é implantada, pune o sistema público de saúde, forçando-o a adaptar-se a orçamentos cada vez mais restritos. Como revela Laurell (1995), os países latino-americanos passam por um processo de implantação da política social neoliberal que, entre outras estratégias, envolve o corte de gastos sociais públicos e a privatização. Decisões políticas como essas ocasionam impacto direto na saúde da população (Raphael et al., 2000).

Em conseqüência ao desfinanciamento, ocorre deterioração e aumento do desprestígio das instituições públicas de saúde, ajudando "a criar a demanda ao setor privado e a tornar o processo de privatização socialmente aceitável" (Laurell, 1995). O Brasil torna-se exemplo disso pois, "à medida que o SUS passou a ser desacreditado, ocorreu o privilégio do atendimento na rede privada conveniada e a ampliação da procura, por parte da população, pelos convênios de seguro médico privado" (Faria; Jatene, 1995).

Desse modo, é evidente a utilização do setor privado pelos que ostentam maior renda e do ramo público pelos menos favorecidos financeiramente. Quando esses que possuem pouca capacidade de pagamento e alto risco de adoecer procuram o setor privado correm o risco de não serem atendidos, enquanto o setor público é obrigado a aceitar todos (Laurell, 1995; Faleiros, 1997).

Conforme Oliveira e Vasconcelos (1992), as políticas de Saúde do Trabalhador estão submetidas ao movimento de forças sociais que influenciam na relação entre Estado e Sociedade Civil. Dessa forma, há necessidade de adaptar o modelo de atenção à Saúde do Trabalhador para "que as medidas capazes de enfrentar e reverter os perfis epidemiológicos de morbimortalidade dos trabalhadores sejam compatíveis com as rápidas transformações sociais e com as mudanças na correlação de forças na dinâmica da relação entre o Estado e a Sociedade Civil".

Apesar das dificuldades, a busca de eficiência na atenção à Saúde do Trabalhador não deve ser utópica, e do ponto de vista da saúde pública e da administração dos fundos públicos é dever prioritário. Profissionais do setor saúde devem priorizar a produção de serviços que atendam às necessidades reais dos trabalhadores (Dussault, 1995; Faria; Jatene, 1995). Para o planejamento das ações e políticas a serem adotadas, é preciso conhecer antes o padrão de utilização dos serviços pelos indivíduos em relação ao perfil de necessidades dos diversos grupos sociais que os demandam. Sabe-se 
que é a necessidade que leva ao uso. No entanto, a necessidade é determinada por fatores que expressam dimensões biológicas e sociais dos indivíduos.

De acordo com Pinheiro e Travassos (1999), sexo, idade, raça e condição social interferem na utilização. As mulheres, os indivíduos em extremos da cadeia etária (pela maior ocorrência de doenças e maior necessidade de prevenção) e pessoas com boa condição social, estariam mais sujeitas a usar os serviços de saúde. Existiriam ainda "fatores capacitantes associados à oferta", são eles: a disponibilidade de recursos humanos e físicos, facilidade de acesso, a forma de financiamento e a forma de pagamento ao prestador.

Na Unicamp, é interessante ressaltar que a sensação de dificuldade em utilizar os serviços pelos trabalhadores é acentuada pelo convívio com centros de excelência no atendimento médico do SUS, como o $\mathrm{HC}$ e toda a área da saúde, sempre sobrecarregados. Aqui, cerca de doze mil servidores realizam tarefas para manter em funcionamento a produção de mão-de-obra, informação e serviços que se constitui finalidade da Universidade Pública. Essas pessoas, direta e indiretamente, estão expostas a fatores que podem causar perturbação à saúde, seja no ambiente de trabalho, seja fora dele.

Justifica-se portanto a necessidade de construção de um modelo assistencial eficiente e específico para essa população. Um modelo alternativo que: seja capaz de interagir com os servidores de forma benéfica para todas as categorias; seja capaz de atender aos anseios dos servidores e de seus empregadores; adote ações preventivas (abrangendo medidas de segurança no ambiente de trabalho e vigilância à saúde); envolva a participação ativa dos usuários no processo decisório; estimule a criação de vínculo entre profissional de saúde e usuário; possua sistema de referência e contra-referência hierarquizado. Um modelo que seja capaz de ajustar a real necessidade do trabalhador e de seus dependentes aos serviços prestados; no qual haja equivalência entre o serviço utilizado (se utilizado) e o valor pago por ele.

\section{CONFIGURAÇÃO DO SISTEMA DE ATENÇÃO À SAÚDE ATÉ 2002}

Após os anos 80, o sistema de atenção à saúde no Brasil adquiriu nova conformação. Esse sistema, conforme a descrição de Giovanella e Fleury (1996), teria forma piramidal e seria composto de três subsistemas com lógica de estruturação, clientelas, complexidade tecnológica e modos de financiamento diversos: o subsistema de alta tecnologia, o subsistema privado autônomo ou de assistência médica supletiva e o subsistema público.

No topo da pirâmide estaria o subsistema de alta tecnologia e alto custo. Embora haja entidades públicas e privadas e também o "mix público-privado" como prestadores, o que se observa é que os grupos sociais mais ricos conseguem acesso privilegiado a esse tipo de serviço. Isso caracteriza esse setor como clientelista e altamente seletivo. Nesse subsistema, de $2 \%$ a $3 \%$ da população certamente consumiriam mais de $30 \%$ dos recursos do SUS (Santos, 1990).

No meio da pirâmide estaria o subsistema privado. Esse subsistema que fornece a seus segurados uma assistência médica supletiva, e responsável por ofertar principalmente maior número de consultas médicas e fornecer atendimento hospitalar, ainda estaria em franca expansão. Entretanto, o próprio contexto social brasileiro impõe limite para o crescimento. Por ser um serviço voltado para a classe média, trabalhadores do mercado formal, grandes e médias empresas e considerar-se que o mercado informal é significante no Brasil, acredita-se que esse setor, em algumas regiões, já possa estar estagnando-se e procurando mecanismos para manter-se.

Na base da pirâmide estaria o subsistema público - representado, também, pelos serviços privados contratados e filantrópicos. Esse setor seria responsável por atender a camada da população de menor poder aquisitivo, de mais baixa renda, com mão-de-obra de menor qualificação e o mercado informal da economia. Além de fornecer atendimento predominantemente ambulatorial e assistência de alta complexidade, o setor público seria responsável ainda por atender também aos casos de urgência e emergência. Enquadramse nessa situação os acidentes de trabalho, os acidentes de trânsito, infartos, lesões decorrentes de tentativa de suicídio. Entretanto, a despeito da justeza dos princípios do SUS, a realidade assistencial expressa mais um desejo que uma realidade (Cecílio, 1997).

\section{CO-GESTÃO}

Um modelo que pode ajustar-se às transformações sociais, por envolver a participação de mais de um elemento, é o de co-gestão, no qual as decisões são democráticas.

A palavra co-gestão significa "gestão em comum; administração ou gerência em sociedade” (Ferreira, 1999). Como também demonstra Silva (1991), o “prefixo co, que entra na formação da palavra co-gestão, designa exata- 
mente que se trata de decisão que não se toma isoladamente, mas com a participação de outra vontade".

Embora mostre a co-gestão no âmbito do estabelecimento e da empresa, Silva (1991) diz que esse princípio está vinculado à participação e não envolve somente os interesses do empregado e do empregador, mas transcende essa relação ganhando presença "em todas as comunidades organizadas de prestígio e representatividade da sociedade".

Muito além das definições e classificações que possam surgir aplicadas a diferentes áreas do conhecimento humano, a palavra co-gestão assume neste artigo o sentido de qualificação de um modelo assistencial que procura meios para instalar-se plenamente. Considerando os aspectos e as possibilidades materiais e intelectuais que a Universidade Pública dispõe, a co-gestão representa a idéia de se organizar os serviços de atenção à saúde no câmpus com a participação, no processo decisório e nas ações em saúde, do leque ampliado de atores sociais envolvidos: Universidade Pública, SUS, profissionais de saúde (provedores dos serviços), e os trabalhadores. Este modelo alternativo, local, co-gerido, longe de ser perfeito, pode ser uma forma de reduzir, na prática, o hiato existente entre a universidade, no conjunto de suas potencialidades, e a realidade das necessidades da comunidade universitária no tocante à saúde.

Destaca-se que os profissionais de saúde no SUS já dispõem de representação no modelo gestor, dividindo com os gestores cerca de $25 \%$ da representatividade dos conselhos. No entanto, na assistência supletiva privada, os profissionais que ministram atendimento não dispõem dessa oportunidade e isso é ressaltado na co-gestão privada como novidade.

Evidências de que a co-gestão na área da saúde funciona são encontradas na administração do Município de São Paulo entre 1989 e 1992, que inovou ao delegar poder de decisão às Comissões de Gestão, transformando a democracia participativa em democracia direta. Isso ocorreu graças à descentralização do poder que estava nas mãos do Estado e passou para as mãos das Comissões de Gestão. Essas eram compostas por representantes dos usuários, representantes dos profissionais da saúde e representantes da administração pública. Assim, usuários e profissionais da saúde passaram a ser co-responsáveis pela gestão pública da saúde. Nos quatro anos do funcionamento desse modelo, os recursos orçamentários destinados à saúde aumentaram de $10,6 \%$ para $15,4 \%$, e $48 \%$ desses recursos eram destinados à área social (Cohn, 1996). No entanto, a falta de continuidade dessa política, quando não foram articuladas gestões de nível local com níveis superiores - estado e federação, comprometeu o setor saúde nos anos seguintes. Em lugar da política de serviços públicos foi adotada a política de privatização por meio de supostas cooperativas autônomas de prestadores de serviços, denominada "PAS" (Plano de Atendimento à Saúde). Essa, além de retroceder a iniciativa anterior, retirou mecanismos sociais de controle previstos no SUS e, segundo Carvalho (2002), possibilitou comprovada corrupção e desperdício de recursos públicos.

A implicação das premissas de universalidade, hierarquia e eqüidade do SUS brasileiro fez com que serviços privados sejam contratados pelo Sistema Público de Saúde para atendimento complementar, ou seja, credenciado pago e submetido à auditoria pelo poder público. No entanto, os trabalhadores ainda contratam, adicionalmente, atendimento e cobertura para serviços de saúde externos ao SUS, sendo chamados então de Serviços Suplementares.

Esses serviços são regulados, no Brasil, pela Agência Nacional de Saúde Suplementar (ANS), embora subordinada ao Ministério da Saúde, não faz pagamentos ou auditoria e atua apenas como agência reguladora. Faz-se portanto necessário, que a contratação desses serviços pelos trabalhadores seja aproximada dos padrões de democracia, governabilidade e transparência que servem de modelo para os serviços de saúde do SUS. Para isso, a estratégia escolhida é a da co-gestão.

\section{OBJETIVO E FONTES DE INFORMAÇÃO}

O presente artigo visa discutir e adaptar um modelo de co-gestão para o provimento de serviços públicos e privados suplementares de saúde em universidade estatal a seus próprios servidores de acordo com as normas legais. Decorre de inquérito realizado em 1998 por Corrêa-Filho et al. (2001) para avaliar a demanda e a utilização dos serviços de saúde pelos servidores da Unicamp. Com o objetivo de ajustar a oferta desses serviços às necessidades dos usuários utilizou-se questionários semi-estruturados, auto-respondidos, que foram enviados aos 12.005 trabalhadores ativos e aposentados com os comprovantes de pagamento. À época, foram devolvidos 3.615 questionários que compuseram o banco de dados da pesquisa. Essas informações foram então disponibilizadas para trabalho subseqüente pela equipe de investigadores do Laboratório de Aplicação em Epidemiologia (Lape). 
Assim, foram agregados dados de literatura Medline e Lilacs sobre: serviços de saúde, políticas de saúde, trabalhadores e saúde pública, e formulou-se, em conseqüência, uma proposta de co-gestão dos serviços de saúde públicos e privados para trabalhadores em Universidade estatal, detalhando atores sociais envolvidos, representatividade e poder de decisão.

\section{ASSISTÊNCIA PÚBLICA À SAÚDE DO TRABALHADOR DA UNICAMP}

Os principais prestadores de serviço à assistência médica do trabalhador da Unicamp são: os Centros de Assistência Médica Ambulatorial (Ceama) vinculados ao Instituto de Assistência Médica ao Servidor Público Estadual (Iamspe); outras clínicas ou hospitais do Sistema Único de Saúde (SUS); o Centro de Saúde da Comunidade (Cecom), o Hospital de Clínicas (HC) e o Centro de Atenção Integral à Saúde da Mulher (CAISM) da Unicamp.

Dos servidores públicos estaduais são descontados 2\% de seus rendimentos brutos que, destinados ao Instituto de Assistência Médica ao Servidor Público Estadual (Iamspe), tornam essa entidade responsável pela assistência médica e hospitalar aos contribuintes e seus beneficiários. Essa contribuição compulsória desses servidores "tem representado a fatia maior da receita do instituto, chegando a corresponder a mais de $80 \%$ de toda a receita" (Lima; Carvalho, 1998). Entretanto, a inexistência de serviços credenciados próximos representa uma realidade com a qual a maioria dos servidores da Unicamp não pode contar. Na capital, o atendimento é feito no Hospital do Servidor Estadual (HSE) e no interior, nos Centros de Assistência Médica-Ambulatorial (Ceama) (Lima; Carvalho, 1998). Segundo Melhem (1998), diante da busca de reformulação do Iamspe, parlamentares estaduais reconhecem a escassez de Ceamas no interior.

Fora do câmpus universitário, os trabalhadores que necessitam de atendimento no SUS buscam Centros de Saúde (CSs) e serviços de Pronto-Atendimento para resolução de seu problema de saúde, e são encaminhados para níveis superiores da hierarquia do SUS quando necessário. Como o SUS é um sistema público, o servidor não paga as consultas que recebe, pois isso já é feito indiretamente quando paga impostos. Já o oposto é observado nos serviços particulares, nos quais o servidor procura uma clínica ou um hospital pertencente a esses serviços e paga pelo atendimento prestado a ele.
O Centro de Saúde da Comunidade (Cecom) é o serviço responsável por prestar atendimento médico e odontológico gratuito a todo o câmpus. Possui estrutura centralizada, subordinada à reitoria da Universidade, não permite a participação do trabalhador e detém-se ao caráter curativo da assistência à saúde. Nele são atendidos os servidores, os universitários, estagiários, professores visitantes, trabalhadores terceirizados e adolescentes estagiários denominados "guardinhas". Esse é prestador de serviços de nível primário e de alguns do secundário e, por não ser uma policlínica especializada, algumas vezes há necessidade de referenciar-se ao Hospital das Clínicas (HC) ou ao Centro de Assistência Integral à Saúde da Mulher (CAISM) nas especialidades não disponíveis no Cecom. Além de atenderem aos encaminhamentos, o HC e o CAISM da Unicamp atendem, em seus serviços de pronto-atendimento, às emergências e urgências dos servidores.

Apesar de o caráter supostamente primário do Cecom, não existe referência estruturada para o nível secundário. Logo, é comum o próprio servidor demandar diretamente a especialidade que julga adequada.

Como revelam Corrêa-Filho et al. (2001), o Cecom foi o serviço mais procurado entre os trabalhadores que necessitaram de atendimento clínico geral nos 15 dias que antecederam o inquérito (Gráfico 1).

De acordo com a Tabela 1, o último serviço mais procurado pelos trabalhadores para atendimentos de saúde geral nos 15 dias que antecederam o inquérito foi o Cecom. Já o HC da Unicamp foi o último serviço utilizado por 4,6\% dos trabalhadores, enquanto a participação dos Ceamas foi inexpressiva.

Quando há necessidade de encaminhamentos para saúde do trabalhador, são feitos sem distinção para as instituições que atendem aos serviços gerais de saúde. Dessa forma, além de enfrentarem a grande demanda do SUS, os trabalhadores correm o risco de não terem a assistência específica para saúde do trabalhador.

Corrêa-Filho et al. (2001) demonstram que, no tocante aos afastamentos do trabalho, dos $16 \%$ que referiram ter se afastado nos últimos 12 meses, 99,6\% estavam vinculados diretamente a doenças. Ainda, $66,7 \%$ dos que tiveram acidente de trabalho com lesões não conhecem o trabalho do representante da Comissão Interna de Prevenção de Acidentes (Cipa).

Cerca de 7,8\% dos servidores sofreram lesão em acidentes no trabalho nos 12 meses anteriores ao inquérito e $5,3 \%$ lembraram ter feito a comunicação de acidente de trabalho (CAT). 
TABELA 1

Distribuição de Docentes e Funcionários da Unicamp, segundo o Último Serviço de Saúde Procurado para Atendimento a Necessidades Clínicas nos 15 Dias que Antecederam o Inquérito Campinas -1998

\begin{tabular}{lcr}
\hline Serviço de Saúde Procurado & Números Absolutos & $\%$ \\
\hline Total & 3.615 & 100,0 \\
Não Necessitou Atendimento & 1.998 & 55,3 \\
Cecom & 483 & 13,4 \\
HC-Unicamp & 165 & 4,6 \\
CAISM & 7 & 0,2 \\
Ceama & 1 & 0,0 \\
Outros Serviços & 222 & 6,1 \\
Ignorado & 739 & 20,4 \\
\hline
\end{tabular}

Fonte: Corrêa-Filho et al., 2001.

\section{GRÁFICO 1}

Distribuição de Docentes e Funcionários da Unicamp, segundo Problemas de Saúde e Atendimento Clínico nos 15 Dias que Antecederam o Inquérito Campinas - 1998

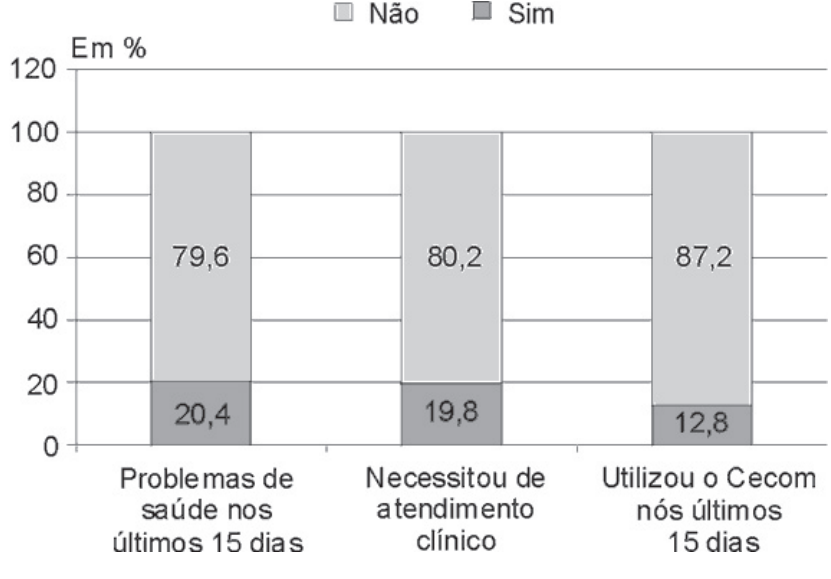

Fonte: Corrêa-Filho et al., 2001.

O estudo realizado por Gentil e Corrêa-Filho (2001) apresenta os afastamentos sofridos pelos trabalhadores da Unicamp, confirmando "a necessidade de dedicar-se atenção especial às condições de trabalho desses funcionários". Os autores alertam para a necessidade de realização de um programa de vigilância em saúde do trabalhador.

Constatou-se que o Cecom, no período 1998-2002, tornou-se uma estrutura centralizada, que não permitiu a participação do usuário e deteve-se no caráter curativo da assistência à saúde, não abrigando o Serviço de Segurança e Medicina do Trabalho (SESMT). O SESMT, que esteve integrado a essa estrutura, foi repassado para o Departamento Geral de Recursos Humanos (DGRH) e tornou-se desvinculado da estrutura prestadora de serviços.

\section{NOVA ESTRUTURA}

Pela necessidade de incorporar o princípio de integralidade do SUS, o modelo proposto não deveria ancorarse somente nas ações de assistência clínica mas englobaria as ações de prevenção de doenças, de promoção da saúde e de vigilância à saúde do trabalhador. Assim, devese buscar a implantação de uma política integrada de promoção da saúde e vigilância em saúde do trabalhador, isto é, a articulação contínua de ações de prevenção e cura.

É necessário distinguir o Serviço de Assessoria Patronal de Medicina do Trabalho - hoje denominado Serviço de Segurança e Medicina do Trabalho (SESMT) do que se propõe neste artigo, ou seja, como um Serviço de Prevenção e Assistência para a Saúde dos Trabalhadores em Co-Gestão.

O primeiro, assemelha-se ao já disposto em Portarias Ministeriais brasileiras. Na presente proposta este serviço manteria suas funções de assessoria patronal mas tornar-se-ia impossibilitado de sujeitar ao exame clínico os funcionários. Por obrigação ética decorrente da lógica da relação médico-paciente, não pode haver um terceiro - o empregador - dominando o contrato de serviço e confiança existente entre um funcionário e um assessor patronal. Como médico-assessor pode ler prontuários mas não examinar pessoas.

O segundo serviço, proposto no presente estudo, por ser co-gerido, teria características de multiprofissionalidade preventiva e assistencial. O mandato do contrato de trabalho estaria governado pelo conselho gestor e teria reavaliação periódica com duração maior que os mandatos dos governantes, no caso dos serviços públicos. A intenção seria impedir demissões e contratações eleitoreiras, conferindo estabilidade relativa aos profissionais.

O trabalhador, em seu papel de cliente do serviço cogerido, pode aceitar ou não ser examinado pelos profissionais de saúde do mesmo. Em caso de não aceitar obrigase a trazer atestados de serviços externos com relatórios de acompanhamento e tratamento caso necessário. Se não desejar nenhum serviço de saúde teria que abrir mão de seus direitos assinando uma desistência, cujo valor jurídico seria questionável.

No caso de um profissional de serviço de saúde do trabalhador receber do cliente exigências ou imposições que não possa aceitar, pode recusar-se a atendê-lo e enviar a outro colega, com a devida justificativa.

A nova estrutura (aqui denominada Centro) ofereceria atendimentos de nível primário e secundário, ilustrados 
na Figura 1. Nesse Centro seriam atendidos servidores da Unicamp, trabalhadores terceirizados, professores visitantes e estudantes da Unicamp. Nesse trabalho, os estudantes são considerados trabalhadores por passarem boa parte de seu tempo estudando em órgão público, financiado pela população, com o objetivo de aprimorar conhecimentos e, ao exercerem a futura profissão, reverter o investimento à sociedade. Portanto, os universitários fazem parte da comunidade beneficiária.

A estrutura proposta contaria com uma porta de entrada no nível primário, comum a servidores e estudantes, que seria responsável pelo atendimento básico e, em casos de necessidade de outra especialidade, direcionamento do cliente para o serviço de referência competente. No caso dos estudantes, o Centro ofereceria somente o atendimento básico, e se houvesse necessidade de outra especialidade seria feito encaminhamento ao nível secundário do SUS, que se encarregaria de seguir as devidas referências. Dessa forma, o Centro atenderia os estudantes apenas no nível primário (Figura 1).

Na questão de procedimentos e serviços de nível secundário, há dúvida de quais deveriam ser disponibilizados pelo Centro, mas a necessidade de uma policlínica especializada (nível secundário) é indiscutível ao serviço. Ela deve ater-se principalmente à manutenção da saúde dos trabalhadores, que ao necessitar de atendimento de nível secundário, não disponível na policlínica, ou nível terciário deveria ser encaminhado ao SUS ou a serviços suplementares. Esses últimos responderiam pelo atendimento de complicações, dificuldades de diagnóstico, doenças crônicas e degenerativas, necessidade de internação e terapêutica especializada.

\section{FIGURA 1}

Esquema dos Níveis de Atendimento à Saúde do Trabalhador da Unicamp e dos Estudantes, Sugeridos para a Nova Estrutura

$$
\text { Campinas }-1998
$$

\section{TRAJETÓRIA DOS TRAJETÓRIA DOS} SERVIDORES UNIVERSITÁRIOS

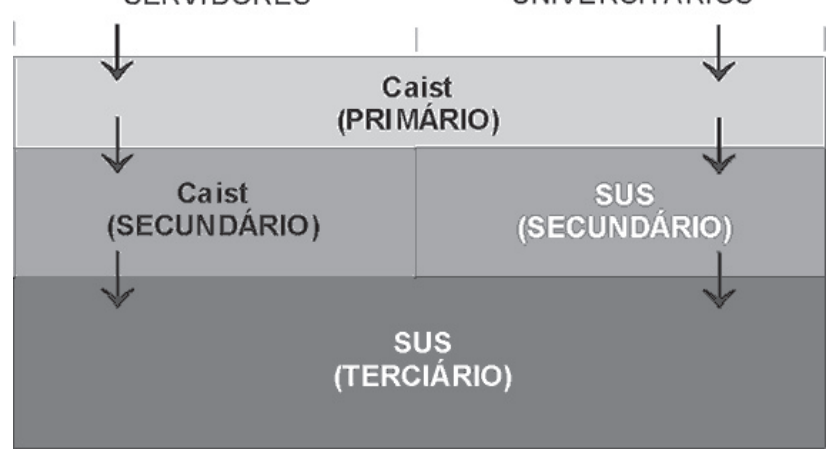

Fonte: Corrêa-Filho et al., 2001.

\section{MODELO PRIVADO SUPLEMENTAR PRESENTE} E A NOVA PROPOSTA

Nos casos em que essas situações ocorrem, o trabalho de Corrêa-Filho et al. (2001) analisa a grande capacidade de contratação de serviços de assistência médica suplementar por parte dos servidores (Gráfico 2). Nesses casos o trabalhador assegura assistência pelo pagamento de planos de saúde ou de seguros de saúde. Nos dois modelos o trabalhador participa pelo pagamento de uma taxa mensal e utiliza os serviços inclusos no contrato. A diferença está no fato de que, quando utiliza um serviço particular, o cliente do seguro-saúde necessita desembolsar o valor do atendimento prestado, e é reembolsado pela seguradora ao apresentar comprovante de utilização e pagamento. Já no plano de saúde o cliente não precisa pagar pelos serviços constantes no contrato quando utiliza serviço particular. Em ambos, é necessário que o serviço de prestação de assistência médica seja credenciado como prestador de serviços do plano ou do seguro. O Gráfico 3 revela que quase $80 \%$ deles têm acesso a sistemas privados. Entre os servidores da Unicamp, no que se refere à cobertura por planos de saúde, 64,2\% possuem a Unimed como plano de saúde; 13,6\% possuem outro plano de saúde; 3,5\% possuem seguro-saúde; $1,5 \%$ possuem seguro-saúde e Unimed. O trabalho revelou ainda que apenas 16,9\% utilizam somente o SUS.

Esses dados revelam quão diferenciada é essa população, já que de acordo com Pesquisa Nacional por Amostra de Domicílios - PNAD/IBGE (Brasil, 1998) 75,5\% da população não é coberta por planos de saúde.

\section{GRÁFICO 2}

Acesso dos Servidores a Serviços Suplementares de Saúde Campinas - 1998

$\square$ Unimed Outros Planos $\square$ Somente SUS $\square$ Ignorado

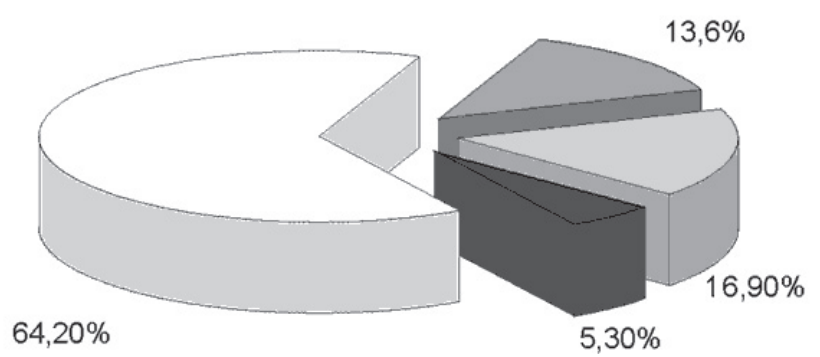

Fonte: Corrêa-Filho et al., 2001 


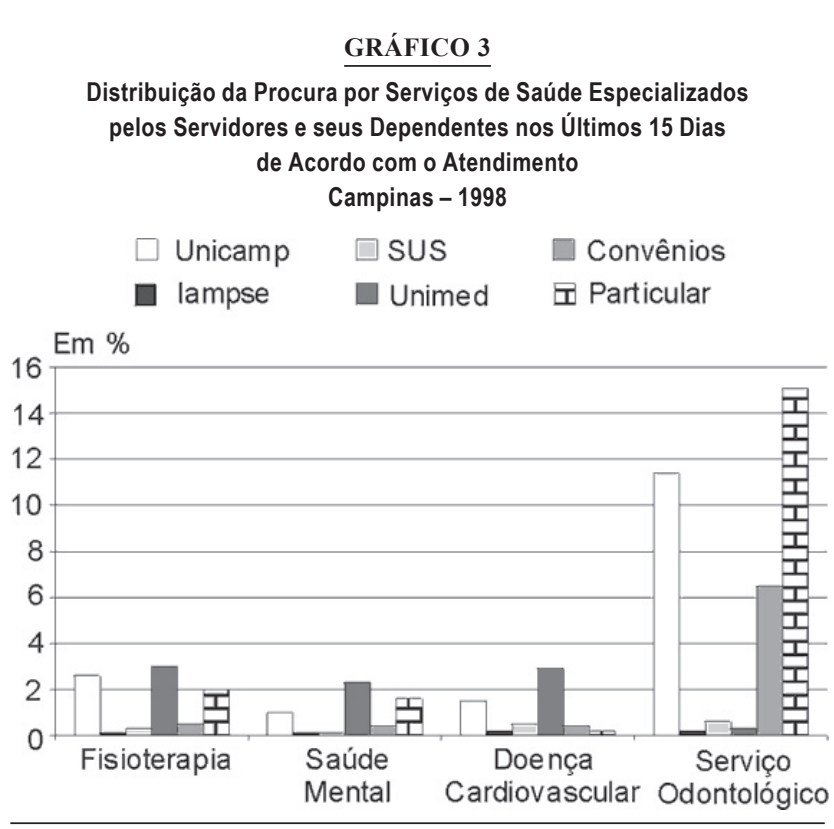

Fonte: Corrêa-Filho et al., 2001.

O Gráfico 3 confirma a maior procura dos trabalhadores por atendimento de saúde especializado nos sistemas privados quando comparada aos serviços públicos. Revela também que, exceto para o atendimento odontológico, os servidores possuem a Unimed como principal provedor de consultas médicas especializadas. Mesmo os servidores possuindo o Cecom, na Unicamp, como provedor de serviço odontológico gratuito, a maioria dos usuários procura atendimento particular, provavelmente em razão da grande demanda e sobrecarga desse serviço.

Os Gráficos 3 e 4 exibem a procura por serviços de saúde especializados pelos servidores e seus dependentes e internações entre SUS e Unicamp - essa separação foi feita apenas para fins de análise: a categoria SUS representa utilização de serviços públicos fora da Unicamp, que também é do SUS.

Quando se observa o percentual de internação de servidores por serviço de saúde nos últimos 12 meses (Gráfico 4) no trabalho de Corrêa-Filho et al. (2001), constata-se mais uma vez a importância dos provedores privados, sobretudo a Unimed.

O percentual de internação foi igual a $17,5 \% \operatorname{nos} 12$ meses que antecederam o inquérito, com nível de confiança de $95 \%$ e sem diferenças significativas entre as diversas categorias profissionais e com relação ao grau de escolaridade.

$\mathrm{Na}$ tentativa de elaborar um sistema de co-gestão alternativo para os servidores que utilizam os sistemas pri-

\section{GRÁFICO 4}

Distribuição de Internações, por Serviço de Saúde nos Últimos 12 Meses Campinas - 1998

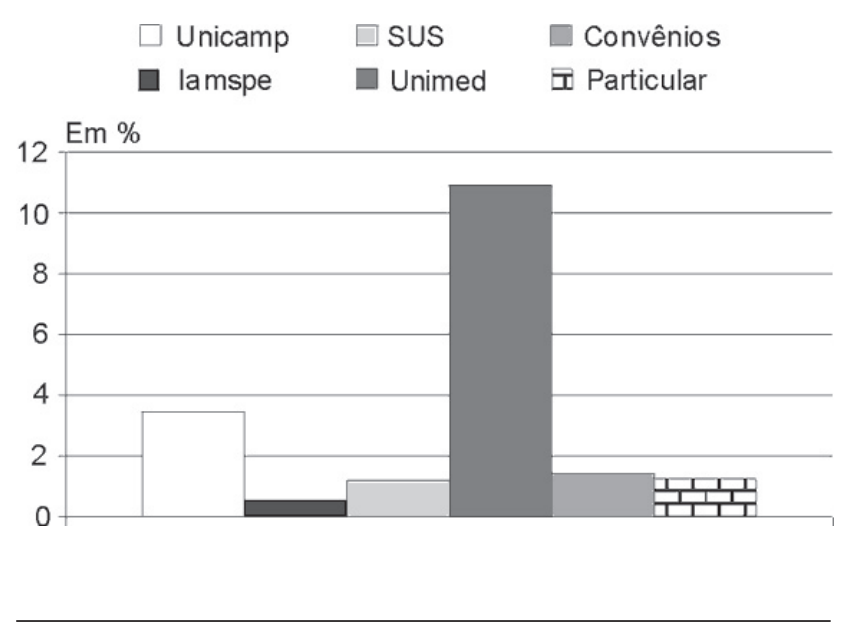

Fonte: Corrêa-Filho et al., 2001.

vados suplementares, o presente trabalho recorre a diversos autores para fundamentar a proposta.

De acordo com Silva et al. (1997): “o papel do setor privado no financiamento e produção dos serviços de saúde, bem como sua articulação com o setor público, constituem-se hoje em uma etapa central do debate sobre as alternativas mais eficazes e menos custosas para a organização setorial em diversos países do mundo".

A Suécia, como muitos outros países, está submetendo-se a uma rápida mudança no sistema de atenção à saúde. Dentro da estrutura de financiamento público, os conselhos locais têm começado a experimentar novos modelos de serviços que incorporem alguns elementos de marketing orientados ao sistema, tais como a competição pública e privada e empreendimentos cooperativos.

Como mostra o estudo comparativo de Hansay et al. (1993), em janeiro de 1988, um centro de cuidados de saúde gerenciado pelo setor privado, entretanto publicamente financiado (study centre), foi estabelecido em uma área do subúrbio de Estocolmo. O contrato entre o empreendedor privado e o conselho local de Estocolmo requeria que os cuidados de saúde fossem fornecidos a uma população geograficamente definida e que o primeiro adotasse os mesmos princípios dos serviços públicos de outras áreas. O cuidado deveria ser baseado então nas principais diretrizes do sistema primário de atenção à saúde sueco, mas o empreendedor deveria decidir como organizar o trabalho. Isso incluía empregar pessoas, custos por 
aluguel, equipamentos. No entanto, a marca do modelo é o afastamento do estado de sua obrigação de prover a assistência. Como resultado básico, observou-se que a redução de gastos esteve associada à restrição de ações preventivas e informativas aos pacientes. Ao tentar substituir o sistema público como provedor de cuidados primários, implantando o sistema privado de cuidado gerenciado (mannaged care), inspirado no modelo americano, a Suécia excluiu a possibilidade de controle social e vinculou perversamente, mais uma vez, a saúde à perspectiva de lucro. Por fim, o modelo sueco teve como base a mera substituição das obrigações dos serviços públicos por privados - levando ao controle de custos sem garantias de que os gastos implicariam qualidade e falhando porque não foi incluída alguma forma de controle social externo.

Existem atualmente, segundo Duarte (2001), quatro modalidades assistenciais principais de medicina supletiva: medicina de grupo, cooperativas médicas, os planos próprios das empresas e o seguro-saúde; cada uma com formas de estruturação, gerenciamento, financiamento e clientelas próprias. Entretanto, nenhuma dessas modalidades, tanto no sistema de pré como no pós-pagamento, envolve formas de representação e participação dos usuários na gestão.

A mescla dessa iminente necessidade dos usuários da assistência médica supletiva com iniciativa reformadora do Estado, que cada vez está mais pronunciada, e os interesses dos profissionais de saúde pode criar uma solução viável para ser aplicada em nível local a uma população adscrita à grande empresa pública.

Um caso de implantação de assistência privada em ambiente universitário, no período 1998-2000, que pode ser parcialmente analisado é o da Universidade Estadual Paulista; "a Unesp, preocupada em instituir um programa de saúde voltado a sua comunidade, abrangendo seus servidores docentes e técnico-administrativos, seus dependentes e o corpo discente, em 1989, instituiu uma Comissão para estudar a implantação do Plano de Assistência Médica e Odontológica na Unesp" (Mais Unesp, 2002). Com base nisso, várias experiências foram realizadas e aprimoradas, incluindo tentativas de contratação de uma empresa especializada para prestação de serviços de assistência médica, hospitalar, cirúrgica, ambulatorial e serviços auxiliares, complementares de diagnóstico e terapia, e a Universidade arcaria com parte do custo escalonado de acordo com os salários dos servidores (Mais Unesp, 2002).

Com base em estudo realizado em 1995 na Unesp, verificou-se que aproximadamente $60 \%$ de seus servidores tinham algum Plano de Saúde, quase $80 \%$ desses por intermédio de alguma associação profissional, e, por causa da inviabilidade - a curto e médio prazo - de incorporar uma despesa dessa magnitude no orçamento da Unesp, julgou-se que a costura de um Plano de Saúde próprio era necessária; para tanto, passaria por amplo acordo entre as associações envolvidas, os servidores interessados, as entidades prestadoras de serviços e a própria Reitoria.

Assim, em junho de 1998, foi realizada uma reunião entre a Pró-Reitoria de Administração (Prad), o Sintunesp, a Adunesp e os representantes das Associações de Servidores, na qual, entre outras coisas, decidiu-se por constituir uma Comissão para estudar um Plano de Saúde viável para as características e as necessidades da comunidade. Desse trabalho surgiu o Mais Unesp - Manutenção e Assistência Integral à Saúde dos Servidores da Unesp (Mais Unesp, 2002).

Considerando as semelhanças entre o trabalho realizado na Unesp e o trabalho realizado na Unicamp por CorrêaFilho et al. (2001), acredita-se que esse seja um momento oportuno para início dos debates sobre um modelo campineiro de assistência à saúde suplementar para os trabalhadores da Unicamp.

Embora seja diferente do modelo de autogestão adotado na Unesp, quanto às formas de representação administrativa, o sistema de co-gestão aqui proposto apresenta como características em comum: não ter finalidade lucrativa, ou seja, o que seria lucro é revertido em benefícios para os usuários; o plano de saúde ser gerado de acordo com as características e necessidades dos usuários; pretender agregar outros tratamentos; pretender alcançar o nível de atenção integral à saúde; propor assistência aos dependentes dos servidores; pretender adotar custos finais bem inferiores aos planos de saúde equivalentes em outras modalidades do mercado; possibilitar o desenvolvimento de programas de prevenção à saúde e de incentivo à qualidade de vida (Mais Unesp, 2002).

No modelo co-gerido, cada um dos quatro grupos envolvidos elegeria periodicamente seus representantes, formando uma comissão tetrapartite responsável pela gestão dos serviços de saúde no câmpus (Gráfico 5). Por permitir a participação ativa e constante de todos, esse modelo facilitaria a disseminação das informações e promoveria maior interesse, principalmente dos trabalhadores, nas discussões relativas à saúde.

Acredita-se hoje que uma das limitações fundamentais do sistema privado é justamente o fato de que o consumidor não conta com a informação e a autonomia de decisão 


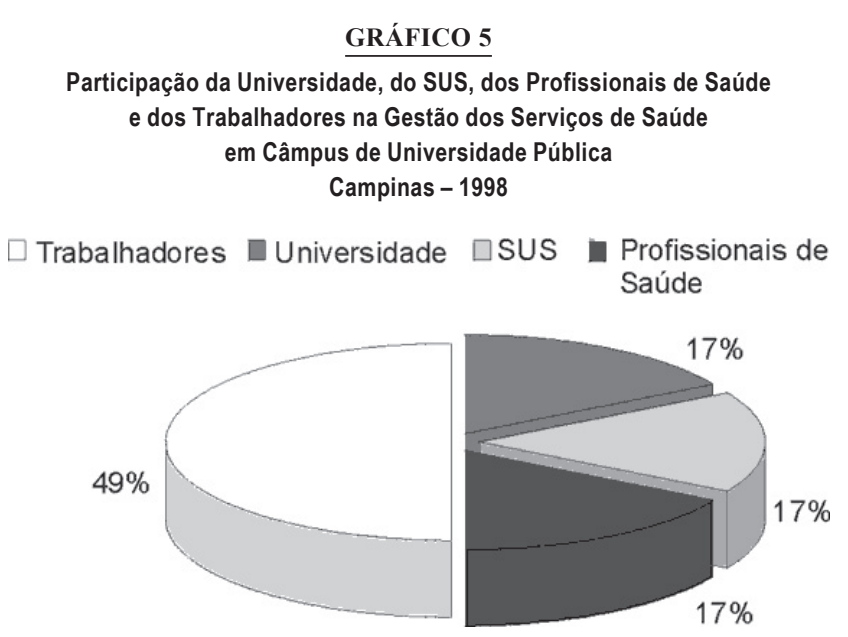

Fonte: Corrêa - Filho et al., 2001

necessárias para eleger o tipo de serviço que necessita, assim como desconhece a prestação mais adequada para resolver seus problemas com menor custo e melhor qualidade. Assim, o prestador controla e influi decisivamente na demanda de prestações com o propósito de aumentar seu lucro e dessa forma maximizar sua ganância (Navarrete et al., 1992).

Diferentemente do serviço privado tradicional, o usuário do modelo aqui proposto deverá ser constantemente informado acerca do funcionamento e da quantidade de recursos que dispõe (equipamentos, exames, especialistas e outros). Além de compreender melhor as atividades desenvolvidas, a co-gestão permite aos usuários compartilhar a decisão de como e onde seus recursos financeiros serão alocados.

Bahia (2001) acredita que "a divisão entre o sistema público e privado segue baseada na idéia de clientes pagantes e não-pagantes". Esse modelo pode possuir um caráter de sistema privado por ser uma forma de assistência à saúde suplementar ao SUS, alternativa aos demais sistemas de atenção médica supletiva, ser destinado a um grupo específico e envolver a participação financeira de seus associados. Entretanto, como não haverá uma empresa responsável pela produção dos serviços com o objetivo de lucro, e por este modelo propor a incorporação e participação de diversos setores da comunidade universitária na gestão, essa modalidade de atenção assume mais um caráter de articulação dos interesses públicos com os interesses de seus servidores. E, neste caso, os interesses não são exclusivamente privados, principalmente se con- siderarmos que a saúde do trabalhador é um fator que o capacita ao trabalho e que a Universidade Pública é o empregador.

O trabalho de Corrêa-Filho et al. (2001), no item prioridades espontâneas, revelou que há um desejo evidente da comunidade universitária de melhoria do sistema de atenção à saúde no câmpus. A inexistência de um serviço de saúde local que atenda de forma rápida às demandas por atendimento de saúde mental, problemas cardiovasculares, nutrição e outros, dos servidores e principalmente de seus dependentes, é uma das razões que os levam à contratação de planos suplementares. Os Gráficos 3 e 4 mostraram que tanto os serviços do Iamspe quanto do SUS são pouco utilizados pelos servidores.

Analisando o setor privado, julga-se, aqui, que a contratação de planos de saúde pelos servidores não é a melhor alternativa para eles, assim como não o é para a universidade pelos seguintes motivos: as modalidades atuais de assistência médica suplementar impedem mecanismos de controle social; não há uma atenção especial às necessidades de toda essa população; e a maioria delas envolve a perspectiva de lucro. Dessa forma, a falta de veículos que permitam a participação dos servidores na gestão desses planos, a atenção à saúde de forma fragmentada e a não potencialização dos recursos concorrem negativamente para configuração de eficientes sistemas de saúde.

Sempre haverá situações e serviços que acabarão desembocando na grande porta, quase sempre sobrecarregada, em que o SUS se constitui. O sistema de saúde privado aqui proposto, co-gerido, local, suplementar ao SUS e alternativo às demais modalidades de assistência médica, pretende, dentro de suas limitações estruturais, minimizar essa porta de saída oferecendo serviços de acordo com o perfil de necessidade dessa população. Não se deseja e não se pretende de forma alguma substituir a atenção terciária fornecida pelo SUS em níveis mais complexos. Pretende-se, apenas, que esse modelo represente uma opção mais eficiente e mais resolutiva para os servidores, podendo ressarcir ao SUS as despesas realizadas com seus usuários e dependentes.

Implantar uma rede de serviços hierárquica que impeça, por exemplo, a consulta direta a médico especialista sem antes passar por generalista; que possibilite a organização de equipes de saúde responsáveis por determinado grupo de servidores e seus dependentes; que promova programas constantes de educação e promoção à saúde; que priorize a atenção preventiva em detrimento da curativa, é fator que pode diferenciar esse modelo privado dos demais. 


\section{MODELO GERAL DE CO-GESTÃO PARA A UNIVERSIDADE}

O modelo proposto para a nova estrutura é o de cogestão tanto para o serviço público de saúde do trabalhador, quanto para o serviço privado suplementar. Propõese a formação de comissões de co-gestão constituídas por representantes do Poder Público, da Unicamp e dos trabalhadores.

O Poder Público é entendido como SUS e Previdência Social. De acordo com a Lei no 8.080 de 1990, a execução de ações de saúde do trabalhador está no campo de atuação do SUS, justificando a atuação desse órgão no modelo (Brasil, 1990a).

A primeira Norma Regulamentadora de saúde do trabalhador apresenta o empregador como responsável pelo que acontece à saúde do trabalhador no âmbito do trabalho, e justificada a participação da Unicamp como empregadora (Brasil, 2002).

Já a participação do servidor é embasada no que foi estabelecido pela Norma Operacional de Saúde do Trabalhador, afirmando: "o direito de participação dos trabalhadores e suas entidades representativas em todas as etapas do processo de atenção à saúde, desde o planejamento e estabelecimento de prioridades, o controle permanente da aplicação dos recursos, a participação nas atividades de vigilância em saúde, até a avaliação das ações realizadas" (Brasil, 1998).

Copiando a representação dos usuários nos conselhos de saúde, a representação dos trabalhadores no modelo de co-gestão será paritária em relação ao conjunto dos demais segmentos, isto é, $50 \%$ de representantes de trabalhadores usuários e $50 \%$ dos demais representantes (Brasil, 1990b).

Como há necessidade de disponibilização de recursos tanto para a implantação como para manutenção do novo modelo, o investimento deverá ser feito pelo Poder Público e pela Universidade em virtude dos trabalhadores serem contribuintes da União, já participando desse investimento para a constituição do SUS. A parcela de participação financeira desses dois co-atores não é discutida aqui, deixando à comissão de gestão a decisão de qual será a parcela que cada um deva empenhar.

No caso da co-gestão privada dos serviços, a forma provável de gestão poderia ser a de modelo cooperativo de usuários de serviços de saúde, com finalidades não lucrativas, podendo ou não receber subsídios de manutenção do poder público. A discussão sobre esse subsídio seria dependente da decisão sobre os descontos para assistência médica que o Estado faz hoje do pagamento dos funcionários. A estipulação de valores é uma tarefa que extrapola as possibilidades desse trabalho. Mesmo assim, acredita-se que o deslocamento da contribuição dos servidores da Unicamp, do Iamspe para um serviço de saúde próprio, já se constitui, de início, fonte provável de divisas. Oliveira e Vasconcellos (1992) já afirmavam que a execução de uma política eficiente de Saúde do Trabalhador deve, além de transpor a formação de quadros tecnicamente competentes e o compromisso com a questão ideológica que envolve a área, atrair a participação do poder público, dos empregadores e dos trabalhadores.

É evidente a presença de conflitos de interesses nesse modelo pois, essencialmente, os trabalhadores desejam atenção adequada à saúde, e a administração da Universidade e o Poder Público buscam constantemente o corte de gastos. Apesar desses conflitos, o modelo de co-gestão (Figura 2), não deve defender interesses de um grupo, mas gerenciar com compromisso social.

Ao serem tomados como compromisso social, saúde e bem-estar social precisam ser buscados pela comissão de co-gestão por meio da instituição e desenvolvimento das ações que a Norma Operacional de Saúde do Trabalhador apresenta, englobando a prevenção de danos à saúde do trabalhador e o atendimento aos possíveis agravos que possa apresentar (Brasil, 1998).

Conforme Oliveira e Vasconcelos (1992), o compromisso de mudança na atual situação de assistência à saúde do trabalhador "deve conter o paradigma do direito à

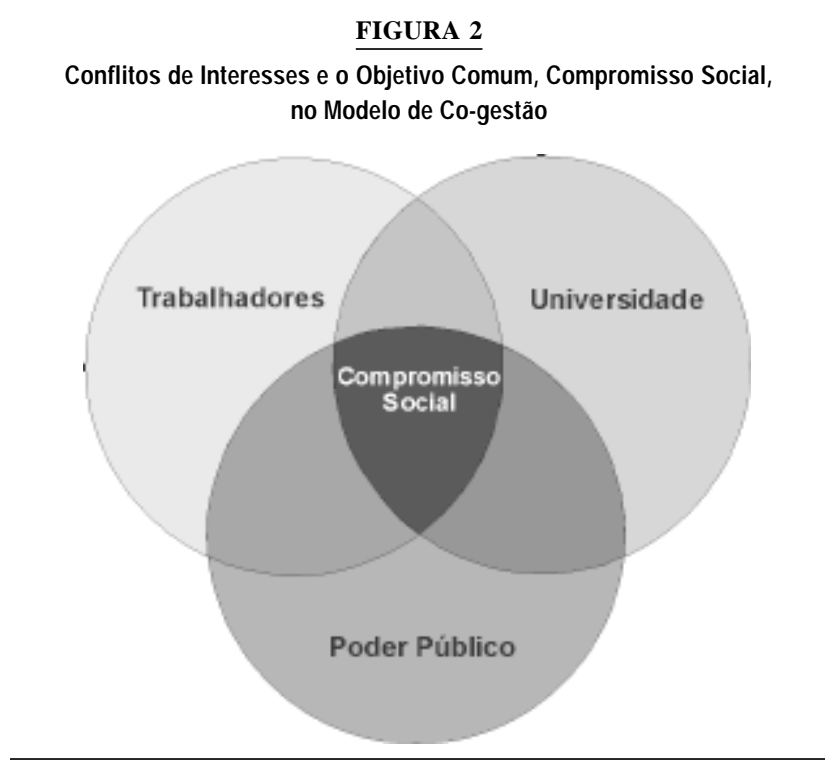

Fonte: Corrêa-Filho et al., 2001. 
vida". Infelizmente, se esse argumento for utilizado como justificativa para a implantação desse modelo, é incerto que o Poder Público e a Universidade reconheçam seus papéis. Então, é preciso recorrer a Riedel et al. (2001), que revelam que o aumento da produtividade é resultado da redução de faltas ao trabalho pela prevenção de doenças e a promoção da saúde, e com a melhoria do desempenho, da criatividade e da motivação causada pela administração de doenças crônicas e agudas. Também apontam que a redução de gastos com saúde é proveniente de intervenções que proporcionem segurança e saúde ambiental, e que possibilitem a incorporação de uma cultura saudável. Contudo, os maiores desafios do sucesso de um programa de prevenção de doenças ou promoção da saúde são conseguir altas taxas de participação e manter a alteração do comportamento com o passar do tempo.

Por vezes, o corporativismo expresso por interesses egoístas imediatos de categorias profissionais impediu o desenvolvimento do trabalho em saúde. A ampliação do conceito de saúde com a formação de uma equipe multiprofissional, responsável por prover os serviços, rompe com o conceito de cooperativa fundado no exercício corporativo das profissões. Em que pese o surgimento de novos fatores sociais que impõem o reconhecimento da importância de condições múltiplas para o estado de "bemestar social", as corporações, entre elas a corporação médica, têm tentado adaptar-se aos novos tempos e novas políticas surgidas com a redemocratização do país e o SUS. Esse movimento é denominado de "neocorporativo" (Ribeiro, 1993). No entanto, a corporação médica não conseguiu ultrapassar a barreira "intra-corporativa", pois se desconhecem referências a cooperativas multiprofissionais de serviços de saúde.

Nesse sentido, propõe-se, para os serviços suplementares privados, a formalização de uma cooperativa não de médicos mas de usuários de serviços de saúde, na qual os profissionais de saúde seriam contratados - médicos, enfermeiros, fisioterapeutas, nutricionistas, psicólogos, terapeutas ocupacionais e outros - e teriam assento às decisões de gestão em proporção compartilhada com a do gestor público - o "patrão" estatal e SUS. No caso das Universidades, o representante patronal estará na dependência de designação pelas reitorias. O SUS já tem suas definições de representação regional estatal definidas em leis e portarias. Esses atores deveriam ter no máximo 50\% do poder de voto, restando aos usuários os outros $50 \%$.

Para Cohn (1996), o poder local pode ser um espaço privilegiado para constituição de uma nova relação da sociedade com o Estado e de construção de novas identidades de sujeitos sociais. A universidade pública pode interagir com esse modelo propondo estudos periódicos sobre prevalência de doenças e afastamentos do trabalho entre servidores do câmpus, realizados por alunos de iniciação científica, especialização ou mestrado, favorecendo o estabelecimento de prioridades. O espaço público precisa ser reconhecido como um ambiente de trabalho que requer intervenções típicas em saúde. A Unicamp, além administrar esse espaço, é o patrão público de grande número de funcionários que contribuem para geração de recursos humanos para a sociedade. Articular-se com os servidores para a construção de um forte sistema de atenção à saúde local torna-se, portanto, um dever.

\section{CONCLUSÃO}

O modelo aqui discutido propõe estabelecer serviço de saúde público e outro privado para trabalhadores da grande empresa pública - a Universidade - com gestão paritária (50\% trabalhadores; $50 \%$ universidade e poder público), seguindo as diretrizes constitucionais e legais do SUS. No serviço privado suplementar propõe-se que os $50 \%$ do poder público e da universidade sejam também compartilhados com representantes dos profissionais de saúde que atendem ao serviço suplementar, ficando portanto cada segmento com $16 \%$ dos votos (Universidade, SUS e profissionais de saúde).

A criação de um Serviço de Saúde do Trabalhador eficiente e de uma Cooperativa Suplementar Privada ofertaria serviços multiprofissionais de saúde capazes de ajustarem-se a novas realidades e sobreviver em momentos críticos. A manutenção deste modelo de saúde do trabalhador requer condições favoráveis e um ambiente social em contínua evolução.

A adoção do sistema de co-gestão representa avanço histórico na mudança de comportamento da Universidade em relação a seus trabalhadores. A existência de mecanismos de controle social sobre a provisão de serviços é uma experiência bem-sucedida que já existe no SUS há anos. Adotar essa prática significa abandonar a posição relutante e omissa que a universidade pública vem mantendo.

O fato de propor-se este modelo não esgota a discussão e pesquisa sobre decorrências sociais, assistenciais e políticas, já que a Saúde do Trabalhador, em espaços submetidos à gerência pública, não tem experiências anteriores no país. 


\section{NOTAS}

PBIC-CNPq/Unicamp 2001-2002. Correspondência para: Unicamp FCM/DMPS - 13.081-970.

Agradecemos à Dra. Joana D'Arc Vieira Neto, diretora do Serviço de Segurança e Saúde do Trabalho, e ao grupo de pesquisa Epidemiologia e Saúde do Trabalhador da Unicamp cujas sugestões feitas foram importantes para a conclusão deste trabalho.

\section{REFERÊNCIAS BIBLIOGRÁFICAS}

BAHIA, L. Planos privados de saúde: luzes e sombras no debate setorial dos anos 90. Ciência \& Saúde Coletiva, São Paulo, Abrasco, v.6, n.2, p.329-339, abr./jun. 2001

BRASIL. Ministério do Planejamento. Instituto Brasileiro de Geografia e Estatística (IBGE). Pesquisa Nacional por Amostra de Domicílios - PNAD. In: . Acesso e utilização de serviços de saúde. Brasília, DF, 1998. Disponível em: <http://www.ibge.gov.br/ibge/default.php>. Acesso em: dez. 2001.

Ministério da Saúde. Portaria Técnica n. 3.908, de 30 de outubro de 1998. Estabelece procedimentos para orientar e instrumentalizar as ações e os serviços de Saúde do Trabalhador no SUS. Brasília: 1998. Disponível em:

<http://www.saude.gov.br>. Acesso em: dez. 2001

Ministério da Saúde. Lei no 8.080, de 19 de setembro de 1990. Dispõe sobre as condições para a promoção, proteção e recuperação da Saúde, a organização e financiamento dos serviços correspondentes e dá outras providências. Diário Oficial [da] República Federativa do Brasil, Poder Executivo, Brasília, DF, 31 dez. 1990a.

Ministério da Saúde. Lei no 8.142, de 28 de dezembro de 1990. Dispõe sobre a participação da comunidade na gestão do Sistema Único de Saúde - SUS e sobre as transferências intragovernamentais de recursos financeiros na área de saúde e dá outras providências. Diário Oficial [da] República Federativa do Brasil, Poder Executivo, Brasília, DF, 20 set. 1990b.

Ministério do Trabalho e Emprego. Saúde e Segurança no Trabalho. In: Normas regulamentadoras de segurança e saúde no trabalho. Brasília, DF, 2002. Disponível em: < http://www.mte.gov.br/>. Acesso em: jul. 2002.

CARVALHO, R.R.P. Credenciamento de médicos no SUS. Jornal do Cremesp. Edição 174, fev. 2002. Disponível em:

<http://www.cremesp.org.br/crmonline/jornalcrm/174/ editorial_0202.htm>. Acesso em: 17 jul. 2002.

CECÍLIO, L.C.O. Modelos tecno-assistenciais em saúde: da pirâmide ao círculo, uma possibilidade a ser explorada. Cad. Saúde Pública, Rio de Janeiro, Fiocruz, v.13, n.3, p.469-478, jul./set. 1997.

COHN, A. Saúde e Cidadania: Análise de uma Experiência de Gestão Local. In: EIBENSCHUTZ, C. (Org.). Política de saúde: o público e o privado. Rio de Janeiro: Fiocruz, p.315-327, 1996.

CORRÊA-FILHO, H.R. et al. Perfil de usuários, utilização e demanda de serviços de saúde da comunidade universitária da Unicamp - Dezembro/1998 - Janeiro/1999. Relatório Técnico de Pesquisa apresentado a: Reitoria da Unicamp; Adunicamp - Associação de Docentes da Unicamp; STU/Unicamp - Sindicato dos Trabalhadores da Unicamp. 2001. Departamento de Medicina Preventiva e Social da Faculdade de Ciências Médicas da Universidade Estadual de Campinas, Campinas, 2001.
DUARTE, C.M.R. Unimed: história e características da cooperativa de trabalho médico no Brasil. Cad. Saúde Pública, Rio de Janeiro, Fiocruz, v.17, n.4, p.999-1.008, jul./ago. 2001.

DUSSAULT, G. Lições da reforma dos sistemas de saúde do Quebec. In: BUSS, P.M.; LABRA, M.E. (Orgs.). Sistemas de saúde: continuidades e mudanças; Argentina, Brasil, Chile, Espanha, Estados Unidos, México e Quebec. São Paulo: Hucitec; Rio de Janeiro: Fiocruz, p.245-259, 1995.

FALEIROS, V.P. Prioridades versus escassez de recursos em saúde. In: SIMPÓSIO A ética da alocação de recursos em saúde. Bioética. Brasília, DF: Conselho Federal de Medicina, v.5, n.1, p.35-40, 1997.

FARIA M.A.M.; JATENE, A.D. (Orgs.). Saúde e movimentos sociais: o SUS no contexto da revisão constitucional de 1993. São Paulo: Edusp, 1995. 215p.

FERREIRA, A.B.H. Novo Aurélio século XXI: o dicionário da língua portuguesa. 3. ed. Rio de Janeiro: Nova Fronteira, p.497, 1999.

GENTIL, G. C.; CORRÊA-FILHO, H.R. Afastamentos por doenças e acidentes - referencial para trabalhadores em universidade. In: CONGRESSO INTERNO DE INICIAÇÃO CIENTÍFICA DA UNICAMP, 9. 2001, Campinas. Caderno de Resumos em CDROM. Campinas: Unicamp, 2001. Disponível em:

<http://www.prp.rei.unicamp.br/pibic/entradaix.html>. Acesso em: jul. 2002.

GIOVANELLA, L.; FLEURY, S. Universalidade da atenção à saúde: acesso como categoria de análise. In: EIBENSCHUTZ, C. (Org.). Política de saúde: o público e o privado. Rio de Janeiro: Fiocruz, p.177-198, 1996.

HANSAI, H.; CALLTORP, J.; ANDRÉASSON, S. Quality Comparisons between Privately and Publicly Managed Health Care Centres in a Suburban Area of Stockolm, Sweden. Quality Assurance in Health Care, Great Britain, Pergamon Press Ltd., v.5, n.1, p.33-40, 1993.

LAURELL, A.C. Avançando em direção ao passado: a política social do neoliberalismo. In: LAURELL, A.C. (Org.). Estado e políticas sociais no neoliberalismo. Tradução R.L. Contrera. São Paulo: Cortez, p.151-158, 1995.

LIMA, M.H.C.; CARVALHO, M.S. Análise organizacional de um subsistema de saúde. In: JUNQUEIRA, L.A.P. (Org.). Reforma do Estado e mudança institucional: o caso do Iamspe. São Paulo: Fundap, p.24-51, 1998.

MAIS Unesp. Manutenção e assistência integral à saúde dos servidores da Unesp. Histórico. 2002. Disponível em: <http://www.maisunesp.com.br/f_hist.htm>. Acesso em: 17 maio 2002.

MELHEM, C.S. O poder das forças políticas e a organização do Iamspe. In: JUNQUEIRA, L.A.P. Reforma do Estado e mudança institucional: o caso do Iamspe. São Paulo: Fundap, p.104-15, 1998.

NAVARRETE, G. et al. Sector privado - Sector público en salud: alternativas para su desarrollo. Cuad. Méd.-Soc, Santiago do Chile, v.33, n.4, p.62-71, set. 1992.

OLIVEIRA, M.H.B.; VASCONCELOS, L.C.F. Política de saúde do trabalhador no Brasil: muitas questões sem respostas. Cad. Saúde Pública, Rio de Janeiro, Ensp/Fiocruz, v.8, n. 2, 1992, p.150-156, abr./jun. 1992.

PINHEIRO, R.S.; TRAVASSOS, C. Estudo da desigualdade na utilização de serviços de saúde por idosos em três regiões da cidade do Rio de Janeiro. Cad. Saúde Pública, Rio de Janeiro, Fiocruz, v.15, n.3, p.487-496, jul./set. 1999.

RAPHAEL, D. et al. Government policies as a threat to health: findings from two Toronto community quality of life studies. Canadian 
Journal of Public Health. Otawa: Canadian Public Health Association, v.91, n.3, p.181-185, May/June 2000.

RIBEIRO, J.M. Arranjos neocorporativos e defesa de interesses do médicos. Cad. Saúde Pública, Rio de Janeiro, Fiocruz, v.9, n.1, p.5-20, jan./mar. 1993.

RIEDEL, J.E. et al. The effect of disease prevention and health promotion on workplace productivity: a literature review. Am. J. Health Promotion, v.15, n.3, p.167-191, jan./feb. 2001.

SANTOS, N.R. O Dilema Estadista II: de como é forjado o espaço das políticas como exemplos da área da saúde. Revista Saúde em Debate, Londrina, Cebes, v.28, n.1, p.5-15, mar. 1990.

SILVA, A.A. Co-gestão no estabelecimento e na empresa. São Paulo: LTr, 1991. 280 p.
SILVA, L.M.V. et al. Algumas características do setor privado de saúde de Salvador, Bahia, Brasil. Cad. Saúde Pública, Rio de Janeiro, Fiocruz, v.13, n.4, p.701-709, out./dez. 1997.

Gilson GeHrIng-JúnIOR: Bolsista de Iniciação Científica PBIC/CNPq -Unicamp - 2001-2002 (gering@fcm.unicamp.br).

Stuart Enes Soares: Bolsista de Iniciação Científica PBIC/CNPqUnicamp - 2001-2002.

Heleno Rodrigues CorrêA-Filho: Professor em Epidemiologia na Unicamp. 